\title{
PERCURSOS URBANOS: UMA ANÁLISE DA ACESSIBILIDADESOB A PERSPECTIVA DAS PESSOAS COM DEFICIÊNCIA VISUAL
}

\author{
MORANO, Raquel Pessoa (1); \\ SANTIAGO, Zilsa Maria Pinto (2) \\ (1) Universidade Federal do Ceará | PPGAU + D |, Mestranda \\ e-mail: raquelmorano20@gmail.com \\ (2) Universidade Federal do Ceará | PPGAU + D |, Doutora \\ e-mail:zilsa@arquitetura.ufc.br
}

\begin{abstract}
RESUMO
Trata da funcionalidade do espaço urbano no que diz respeito às condições de mobilidade e acessibilidade dos pedestres, com ênfase nas pessoas com deficiência visual (PcDV). Objetiva avaliar as condições de acessibilidade para estas pessoas. Recorte espacial - trecho da Avenida Bezerra de Menezes - corredor de grande fluxo em Fortaleza, após obra viária concluída em 2015. A metodologia se apoiou em: Entrevistas; Avaliação Pós-Ocupação; Passeio acompanhado e Percursos comentados. A metodologia foi importante para o entendimento de como as PcDV se relacionam com a cidade, permitindo, ainda, uma melhor comparação das referências normativas e o que realmente está sendo aplicado na cidade.
\end{abstract}

Palavras chave: Acessibilidade; Mobilidade urbana; Deficiência visual.

\begin{abstract}
It deals with the functionality of the urban space with regard to the mobility and accessibility conditions of pedestrians, with an emphasis on visually impaired people. It aims to assess accessibility conditions for these people. Space cut - stretch of Avenida Bezerra de Menezes - large flow corridor in Fortaleza, after roadworks completed in 2015. One methodology was based on: Interviews; Post-occupation evaluation; Guided tour and Commented routes. A methodology was important for understanding how the visually impaired person interacts with the city, allowing a better view of the normative references and what is being applied in the city.
\end{abstract}

Keywords: Accessibility; Urban mobility; Visual impairment.

\section{INTRODUÇÃO}

Nas últimas décadas, a temática da acessibilidade recebeu crescente atenção por parte de órgãos públicos, profissionais de Arquitetura e Urbanismo, juntamente com o setor de construção e população em geral. A criação do Ministério das Cidades, em 2003, marcou um novo período no histórico das políticas públicas no país. Dentre os demais setores de competência do Ministério, surge a Secretaria Nacional de Transportes e Mobilidade Urbana (SeMob), que apresenta como pressuposto básico para a mobilidade urbana "a garantia da acessibilidade e do exercício dos direitos fundamentais do ser humano e a capacidade de deslocamento das pessoas no meio urbano" (SeMob, 2007). 


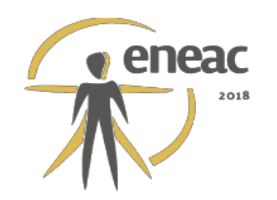

O Decreto ํ․ 5.296, de 2 de dezembro de 2004, é também importante marco regulatório, torna efetivas as leis de no. 10.048/2000, que determina a prioridade no atendimento para as pessoas com deficiências, bem como a lei $\mathrm{n}^{\circ}$. 10.098/2000, que promove a acessibilidade através de normas gerais e critérios básicos nas edificações de uso coletivo, edificações públicas, nos sistemas de comunicação e sinalização.

Em 2012, o Governo Federal cria o Plano Nacional de Mobilidade Urbana (PNMU), promulgado na Lei ํ․ 12.587, foi um marco importante no que se refere à mobilidade $\mathrm{e}$ acessibilidade no espaço urbano (SANTIAGO; DO NASCIMENTO, 2014). O PNMU define acessibilidade como "facilidade disponibilizada às pessoas que possibilite a todos, autonomia nos deslocamentos desejados", e tem por objetivo "contribuir para o acesso universal à cidade" (BRASIL, 2012).

A recente revisão da NBR 9050, concluída em 2015, traz avanços consideráveis, dentre eles, o conceito de desenho universal que aparece nos anexos de uma forma mais ampla levando em consideração uma arquitetura e um design mais inclusivos e "centrados no ser humano e na sua diversidade" (NBR 9050/2015, p.139).

A cidade de Fortaleza também apresenta avanços na legislação municipal e ações positivas como a produção do Guia de Acessibilidade (2009). Apesar de ser uma medida positiva, Fortaleza ainda é considerada como uma cidade repleta de problemas em relação à acessibilidade. Frente a esta realidade, faz-se necessário averiguar que medidas estão sendo tomadas para a alteração deste quadro e avaliar a funcionalidade do espaço urbano produzido por tais ações ou ausência delas. Neste sentido, o presente trabalho, que faz parte de pesquisa em andamento, objetiva avaliar as condições de acessibilidade para pessoa com deficiência visual, tendo como recorte espacial, um trecho da Avenida Bezerra de Menezes em Fortaleza, após obra viária promovida pelo Programa de Transporte Urbano de Fortaleza (TRANSFOR) concluída em 2015.

A Avenida Bezerra de Menezes foi escolhida por abrigar as principais escolas para Pessoas com Deficiências Visual, o que torna a análise das condições de acessibilidade imprescindível para avaliar e apresentar diagnóstico relacionado as questões físicas e qualitativas do lugar. Em 2012, a Avenida passou por uma primeira grande reforma e sua acessibilidade foi avaliada pelas autoras Zilsa Santiago e Raquel do Nascimento ${ }^{1}$, cuja pesquisa servirá de comparação da situação atual.

Essa análise só foi possível devido ao aporte de conteúdo apresentado e debatido na disciplina de Estágio Docência do Programa de Pós-Graduação em Arquitetura, Urbanismo e Design realizado na disciplina de Desenho Universal da Graduação em Arquitetura e Urbanismo da Universidade Federal do Ceará, além da contribuição dos alunos da disciplina que foram a campo e contribuíram com suas análises e vistorias. Foi utilizado como base para definição dos critérios de comparação e análise os princípios, normas e leis sobre o assunto (NBR 16537/2016; NBR 9050/2015; CEARÁ, 2009) dentre outras referências (DISCHINGER, 2000; THIBAUD, 2002; RHEINGANTZ et al, 2009; SANTIAGO e DO NASCIMENTO, 2014).

\section{METODOLOGIA}

Caracterizada como pesquisa qualitativa, envolve obtenção de dados descritivos sobre pessoas, lugares e processos interativos pelo contato direto do pesquisador com a situação estudada, procurando compreender os fenômenos segundo a perspectiva dos sujeitos, ou seja, dos participantes da situação em estudo (GODOY, 1995).

\footnotetext{
${ }^{1}$ Artigo apresentado no ENEAC em 2014 em forma de artigo intitulado "Avaliação das Condições de Microacessibilidade Física na Avenida Bezerra de Menezes Pós-Transfor"
} 


\section{remen $^{-1}$}

Por todo o caráter qualitativo, foram escolhidas metodologias consagradas para 0 desenvolvimento do trabalho. A Avaliação Pós-Ocupação (APO), segundo Rheingantz et al (2009), possui oito ferramentas, que são: Walkthrough; Mapa comportamental; Poema dos desejos; Mapeamento visual [mapa cognitivo]; Mapa Mental; seleção visual; Entrevistas e Questionário. Neste trabalho foram utilizadas as seguintes ferramentas da APO: Walkthrough, Mapa Mental que se fundirá com Mapa Sensorial e, para complementar o Walkthrough, foram aplicadas as metodologias: Passeio Acompanhado (DISCHINGER, 2000), Percursos Comentados (THIBAUD, 2002) e Entrevistas.

Assim, estas metodologias foram importantes para o entendimento da relação pessoa-lugar, bem como, para assinalar aspectos positivos e negativos do ambiente, visando a melhoria dos espaços públicos, em especial, para aqueles que a acessibilidade urbana é indispensável para sua mobilidade.

\section{CARACTERIZAÇÃO DO OBJETO DE ESTUDO}

\subsection{Avenida Bezerra de Menezes}

A Avenida Bezerra de Menezes está situada na porção oeste da cidade de Fortaleza, na divisa das Secretarias Executivas Regionais I e III (Figura 1). A via possui cerca de 3,3 km de extensão e tem sua continuidade na Avenida Mister Hull, que em seguida se transforma na BR 222, ligação com outros municípios no norte do Estado.

Figura 1 - Mapa das Secretarias Executivas Regionais de Fortaleza - localização da Avenida Bezerra de Menezes

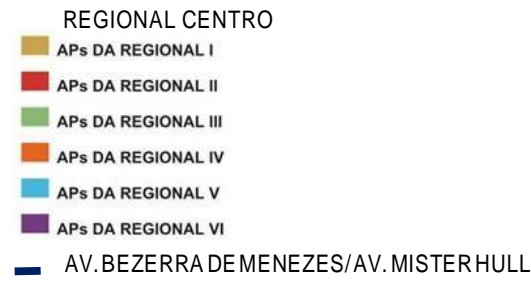

Fonte: Morano, 2017

Ao longo da avenida podem ser encontradas diversas atividades urbanas, e por isso, formou uma área de grande atração de usuários de bairros vizinhos. Existem equipamentos de grande relevância para a cidade, como: North Shopping e o Campus do Pici. Além desses, existem colégios, bancos, igrejas e mercados (SANTIAGO; DO NASCIMENTO, 2014) que geram fluxo e atraem milhares de usuários diariamente. Em destaque, ressaltamos três equipamentos de grande relevância para o público contemplado nesse artigo, que são: Sociedade de Assistência ao Cego; a Associação dos Cegos do Estado do Ceará e o Instituto dos Cegos Hélio Goes. A escolha desta via se justifica, além da presença destas entidades, por ter sido reformada, em que cada sentido da avenida passa a ter cinco estações para ônibus articulados e de grande porte, que garantem maior acessibilidade aos passageiros com deficiências físicas.

Em 2012, foi entregue uma das obras do TRANSFOR - pacote de obras viárias para a cidade de Fortaleza financiado pelo Banco Interamericano Desenvolvimento (BID) - 0 corredor de transporte exclusivo que interligou o Terminal do Antônio Bezerra ao Terminal do Papicu. A Avenida Bezerra de Menezes foi uma das primeiras vias na qual o projeto executado. Nela foram feitos: obras de drenagem; terraplanagem; pavimentação; sinalização horizontal e vertical; padronização de calçadas e canteiro central; iluminação pública; túnel e ciclovia. Além disso, a avenida recebeu o projeto piloto do plano de implantação do Bus Rapid Service (BRS), com faixas de circulação exclusivas para transporte público coletivo e táxis. O número de paradas de ônibus passou de 19 para 13 e, 


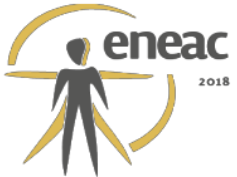

todas dotadas de abrigo para os usuários de transporte público, além disso, foram retirados os estacionamentos das calçadas (SANTIAGO; DO NASCIMENTO, 2014).

Em 2015, o projeto piloto do BRS foi posto em vigor e trouxe consigo algumas modificações na configuração da via, como: a instalação de corredores exclusivos de ônibus Bus Rapid Transit (BRT) - transferindo as paradas de ônibus para o canteiro central; de acessibilidade e arborização. Segundo a Prefeitura, o objetivo da implantação do corredor é diminuir o tempo de viagem e dar maior qualidade ao transporte público coletivo.

Por ser uma avenida que se liga ao centro da cidade, existem dezenas de linhas de ônibus que passam por ela, tanto municipais quanto metropolitanos, com uma média de 300 veículos por hora e 187 mil usuários e dezenas de milhares de veículos particulares (SANTIAGO; DO NASCIMENTO, 2014). Em 2014, a Av. Bezerra de Menezes ocupava o terceiro lugar no ranking de volume diário de veículos. Hoje, segundo a AMC, a avenida ocupa o primeiro lugar, sendo de extrema relevância para a cidade.

Para esse artigo, foi feito um recorte/percurso para ser estudado com mais detalhe. Isso foi feito, pois, há uma repetição dos elementos - distância entre as paradas, recuos, calçadas ao longo da via. Além disso, a área escolhida foi uma das que tem maior fluxo de Pessoas com Deficiência Visual, pois fica próximo ao Instituto dos Cegos.

Figura 2: Localização do trajeto na cidade

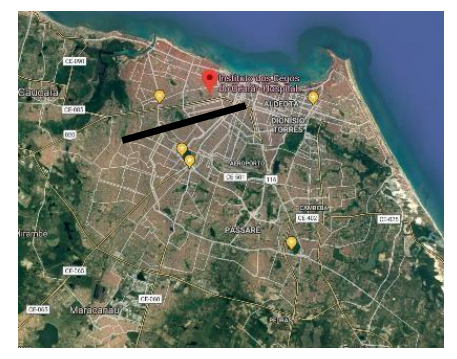

LEGENDA

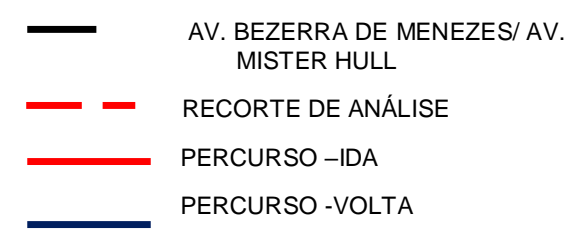

Figura 3 e 4: Área recorte de análise

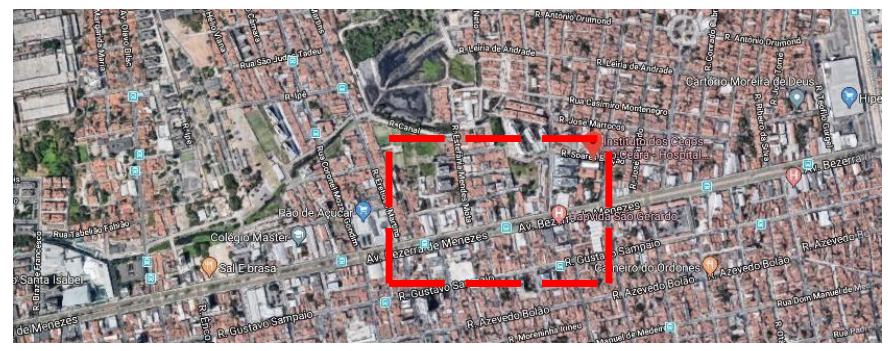

Fonte: Google Earth editado pelas Autoras.

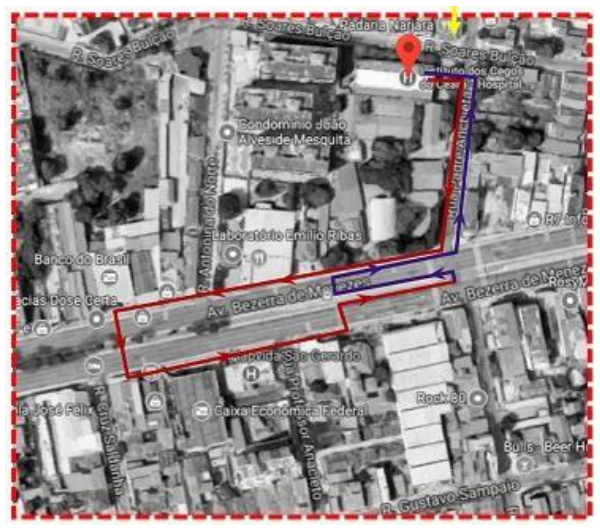

Fonte: Google Earth editado pelas Autoras.

Para realização do percurso contamos com a participação voluntária dos alunos da disciplina de Desenho Universal da Universidade Federal do Ceará e dos alunos do Instituto dos Cegos Hélio Goes. Dias antes de fazer o percurso com os alunos e voluntários, foi realizado um reconhecimento da área, conhecimento das dinâmicas, fluxos e comportamento das pessoas que transitam por ali, bem como verificado a melhor forma de fazer o Percurso Comentado e Passeio Acompanhado. Através desse reconhecimento da área, foi feito um Checklist para avaliação dos parâmetros normativos que foram considerados relevantes, contudo, pela extensão da pesquisa, para este artigo serão apresentados apenas os seguintes critérios de análise: calçadas, piso tátil, sinalização, vegetação. 


\section{reme $^{\text {reme }}$}

\section{DISCUSSÃO E RESULTADOS}

Na visita à área de estudo foi precedida por um encontro das autoras acompanhadas dos alunos da Disciplina de Desenho Universal (DU) da UFC com alunos voluntários do Instituto dos Cegos Hélio Goes. Estes últimos, ao todo, foram 10 alunos voluntários, dentre eles, Pessoas com Baixa Visão e com Cegueira Total; homens e mulheres de faixa etária que variou de 24 a 65 anos. As entrevistas aconteceram individualmente e simultaneamente. Então, cada grupo entrevistou um PcDV. À medida que acabavam uma entrevista, começava outra até que todos fossem entrevistados. Dar a oportunidade para essas pessoas contarem suas histórias, falarem sobre as dificuldades de seu dia-a-dia. É uma etapa importante para o entendimento de como outros fatores influenciam na relação da PcVD com a cidade.

Após as entrevistas, nos dirigimos para iniciar o Percurso. Vale salientar que alguns dos voluntários já conheciam o trajeto. Nessa parte, usamos a metodologia do Passeio Acompanhado e do Percurso Comentado, antes de iniciarmos o Percurso, explicamos sobre a importância da fala de cada sensação ao longo do caminho. A explicação das sensações corporais e percepção do espaço físico são de grande valia, pois, permite identificar simultaneamente 0 que o participante está falando e, assim 0 entendimento das necessidades, dificuldades, facilidades e carências ficam evidentes e compreensíveis. Para essa etapa foram utilizados registros fotográficos e de vídeos.

\subsection{Calçadas}

$\mathrm{Na}$ pesquisa, foram levados em conta itens, como: material do piso e seu estado de conservação; faixa para travessia de pedestres; rebaixamento de calçada para travessia de pedestre; faixa elevada; alinhamento de rampa com faixa de pedestre; obstáculos; sinalização com piso tátil e faixa de serviço, livre e de acesso.

$\mathrm{Na}$ via analisada, estão presentes algumas recomendações da Norma (NBR 9050) e do Guia de Acessibilidade (2009), como por exemplo, a padronização das calçadas. Segundo Santiago e Do Nascimento (2014), na reforma concluída em 2012, a troca de piso para a padronização das calçadas já tinha sido realizada e executada "com piso cimentado e blocos pigmentados intertravados de concreto" (Foto 1 e 2).

Em relação ao tipo de piso, a NBR 9050/2015 recomenda que

os materiais de revestimento e acabamento devem ter superfície regular, firme, estável, não trepidante para dispositivos com rodas e antiderrapante, sob qualquer condição (seco ou molhado). Deve-se evitar a utilização de padronagem na superfície do piso que possa causar sensação de insegurança (por exemplo, estampas que pelo contraste de desenho ou cor possam causar a impressão de tridimensionalidade) (NBR 9050/2015, p.55).

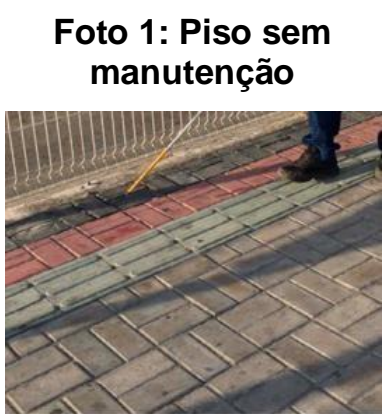

Fonte: Morano, 2017
Foto 2: Piso sem manutenção

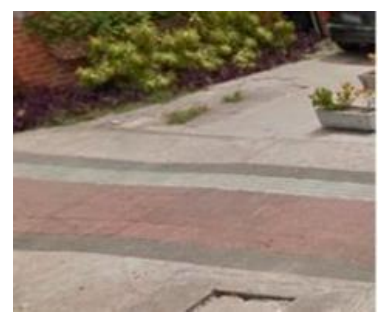

Fonte: Morano, 2017

\section{Foto 3: Piso sem manutenção}

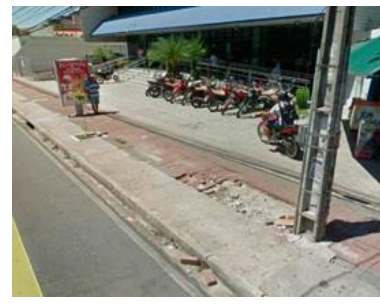

Fonte: Morano, 2017

Neste sentido, a padronização do piso das calçadas está em conformidade com a Norma. Visto que a via foi reformada recentemente, em alguns lugares o piso estava conservado, 


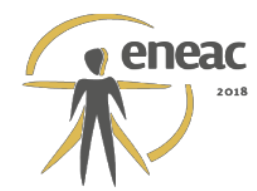

porém foram identificadss partes quebradas ao longo do percurso, dificultando o percurso das PcDV e impossibilitando a passagem de cadeirantes (Foto 3).

As faixas de utilização das calçadas, segundo o Guia de Acessibilidade (2009), devem ser divididas em três faixas distintas para melhor entendimento e uso, são essas: faixa de serviço, faixa livre e faixa de acesso. Os tamanhos dependerão da área disponível da calçada. No caso do trecho analisado, a faixa de serviço apresenta uma dimensão entre 0,90 e 1,10 metros e é feita de piso cimentado. A faixa livre possui uma dimensão de 1,30 a 1,70 metros e é feita de piso intertravado. A faixa de acesso possui seu tamanho variado ao longo da via, pois depende do recuo das edificações.

Foto 4: Obstáculos na faixa livre

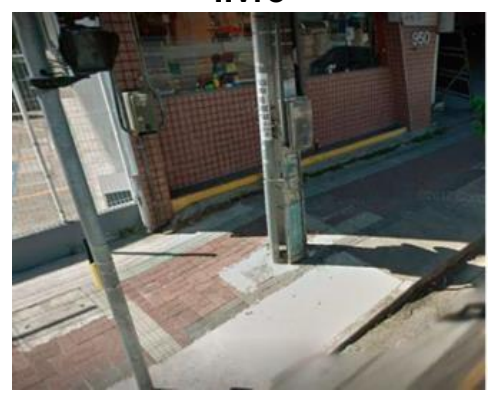

Fonte: Morano, 2017
Foto 5: Placa de trânsito

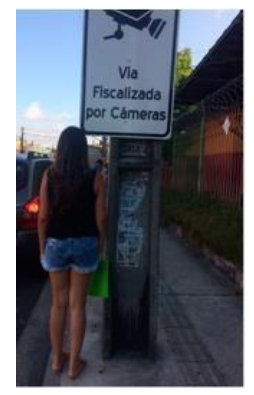

Fonte: Morano, 2017

\section{Foto 6: obstáculos antes da faixa de pedestre}

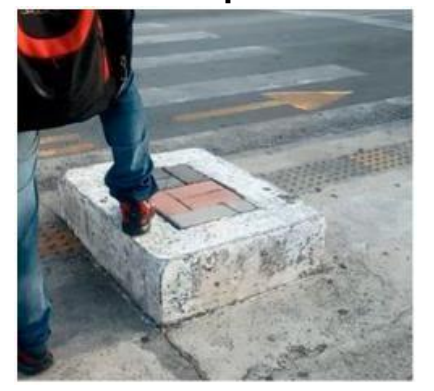

Fonte: Morano, 2017

Segundo a NBR 9050:2015, "a faixa livre ou passeio destina-se exclusivamente à circulação de pedestres, deve ser livre de qualquer obstáculo, ter inclinação transversal até $3 \%$, ser contínua entre lotes e ter no mínimo 1,20 m de largura e 2,10 m de altura livre", sendo assim, com uma largura entre 1,30 e 1,70 metros, a faixa no percurso analisado, está de acordo com a norma. Porém, em vários trechos, foram vistos obstáculos na faixa livre. Esse é considerado um ponto crítico, principalmente, para os usuários que possuem Deficiência Visual, pois além de alguns obstáculos estarem abaixo de 2,10 m, conforme exige a norma, não há sinalização de alerta adequada para que as PcDV não se machuquem. Além disso, foi visto alguns pontos de "estrangulamento" de passagem, vários obstáculos muito próximos um do outro, dificultando a passagem de todos os pedestres e impedindo 0 percurso de alguns.

Dentre os obstáculos fixos mais presentes, estão: postes de energia (Foto 4); placas de trânsito (Foto 5); caixa de esgoto; canteiros para vegetação; telefone público e sinalização vertical. Ao atravessar, existem alguns obstáculos para que os carros não invadam o espaço do pedestre (Foto 6), porém, para a PcDV, é mais uma barreira. A análise dos obstáculos serviu para mostrar o quanto esta população precisa redobrar a atenção no caminhar pela cidade. Os obstáculos são um dos maiores causadores de acidentes de PcDV no espaço público, principalmente, os verticais e sem sinalização no piso. A norma NBR9050/2015 e o Guia de Acessibilidade (2009) orientam a colocação desses elementos na faixa de serviço, e quando não há faixa de serviço, que sejam devidamente sinalizados com piso tátil de alerta.

Para as pessoas com baixa visão, o tipo de piso apresenta importância tanto pelo seu tipo quanto pela sua cor. A padronização do piso é imprescindível para essas pessoas, pois facilita o entendimento do caminho em relação à presença de degraus e buracos. Em relação à cor, o contraste é algo relevante, pois realça a presença de piso tátil, buracos e qualquer interrupção que possa haver no caminho. Foi constatado que a calçada exige que as PcDV estejam alertas, isso por apresentarem grande número de obstáculos - fixos ou não. Muitos dos obstáculos fixos são colocados pelos próprios órgãos municipais. 


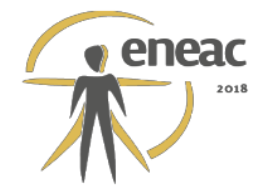

\subsection{Piso Tátil}

O piso tátil é destinado especialmente para as PcDV, a fim de ajudar na orientação, direcionando para algum lugar e alertando de possíveis obstáculos. Sabendo disso, a análise se fez importante, principalmente, para sabermos como o usuário o utiliza e o entende.

De acordo com a NBR 16.537/2016,

A sinalização tátil direcional ou de alerta no piso deve ser detectável pelo contraste de luminância (LRV) entre a sinalização tátil e a superfície do piso adjacente, na condição seca ou molhada. A diferença do valor de luminância entre a sinalização tátil no piso e a superfície adjacente deve ser de no mínimo 30 pontos da escala relativa. Deve ser evitado o uso simultâneo das cores verde e vermelha (NBR 16.537/2016, p. 9)

Além disso, explicita que o contraste visual tem como função destacar elementos entre si por meio da composição claro escuro ou escuro-claro para chamar a atenção do observador. Foi verificado que isto não acontece na calçada das proximidades do Instituto dos cegos (Foto 7). Segundo a mesma NBR, a sinalização tátil e visual de alerta no piso deve ser utilizada para: a) informar à pessoa com deficiência visual sobre a existência de desníveis c) informar as mudanças de direção ou opções de percursos; f) indicar as travessias de pedestres. Além de haver interrupções do piso tátil, há também piso direcional colocado na direção equivocada (Foto 8) - de acordo com a NBR 16537/2016 "a sinalização tátil direcional deve ser posicionada de acordo com o fluxo de pedestres."

A sinalização tátil das rampas de acesso à plataforma está de acordo com a NBR $16.537 / 2016$ quando diz que "a sinalização tátil de alerta deve medir entre $0,25 \mathrm{~m}$ e $0,60 \mathrm{~m}$ na base e no topo de rampas, com inclinação i>5\%. Contudo, foi visto que o piso tátil está em desconformidade com as Normas em muitos pontos do percurso. Seja nas travessias ou alertando barreiras. Além disso, há dificuldade das PcDV de localizarem o piso, ou por estarem desgastados, ou por estarem posicionados ao lado de pisos com textura, deixando a trepidação da bengala quase que uniforme. Porém, quando encontrados, muitos usuários se sentem seguros com sua presença, ao ponto de caminharem em cima do piso (Foto 9) que é uma maneira equivocada de usá-lo, segundo o professor de Orientação e Mobilidade do Instituto dos Cegos -, mas o fazem pois, como existem muitos obstáculos nas calçadas, o piso tátil é sinônimo de segurança, pois acreditam que não vai haver nada sobre este piso mas, em alguns casos, há.

Foto 7: Piso direcional sem contraste de cor

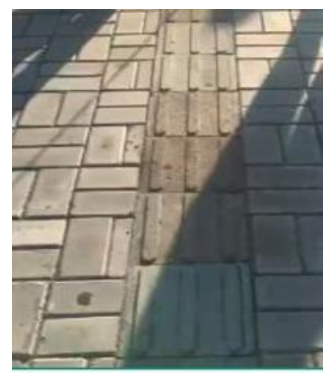

Fonte: Morano, 2017
Foto 8: Piso direcional inadequado

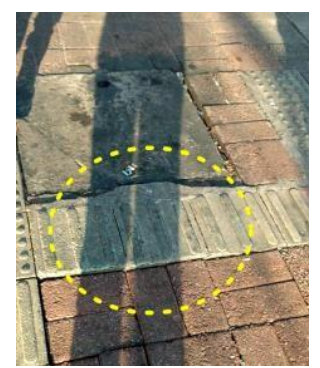

Fonte: Morano, 2017
Foto 9: Piso direcional $x$ mobilidade

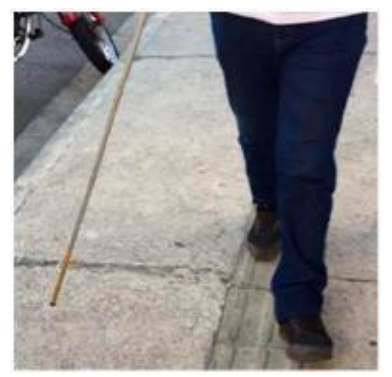

Fonte: Morano, 2017

\subsection{Sinalização}

É visto que o sinal sonoro está presente em todas as travessias do percurso da Av. Bezerra de Menezes, porém, não há sinalização em Braile nos sensores de ativação e, nem nas 


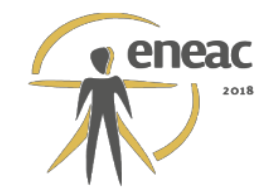

placas (Foto 10 e 11). Nas plataformas, existe um painel de informações em Braile que foi testado pelos participantes e está em boas condições de uso e leitura (Foto 12).

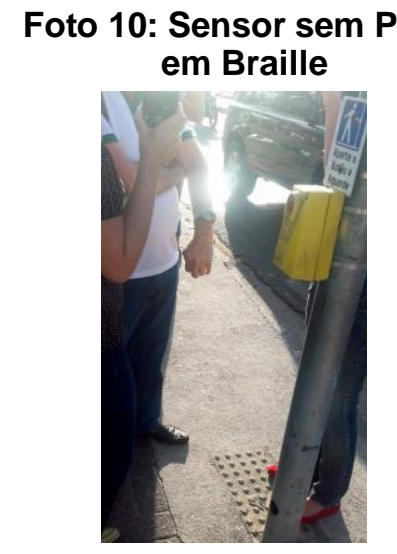

Fonte: Morano, 2017

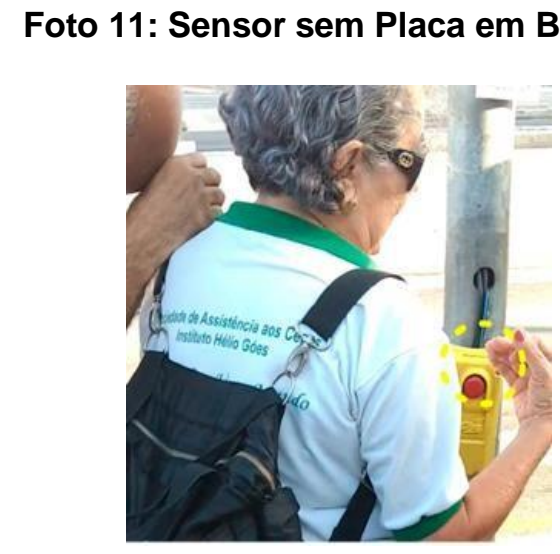

Fonte: Morano, 2017
Foto 12: Painel de informações em Braile

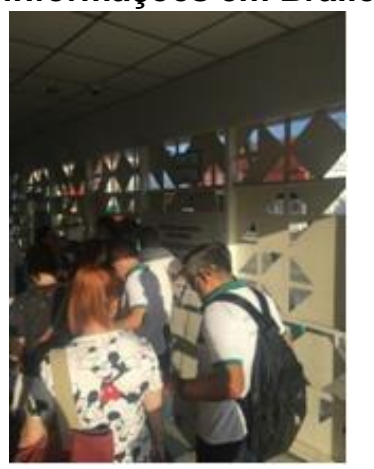

Fonte: Morano, 2017

Ainda sobre o Sinal Sonoro, segundo a NBR 9050/2015, "o tempo de travessia de pedestres deve estar adequado à marcha de pessoas com mobilidade reduzida de $0,4 \mathrm{~m} / \mathrm{s}$.". Com o passeio acompanhado, foi verificado que o tempo do sinal é inferior ao necessário para uma travessia tranquila e segura, assim, força o pedestre, principalmente a PcDV - por se sentir insegura em relação ao tempo - a parar no canteiro central e esperar pelo próximo sinal sonoro (Foto 13).

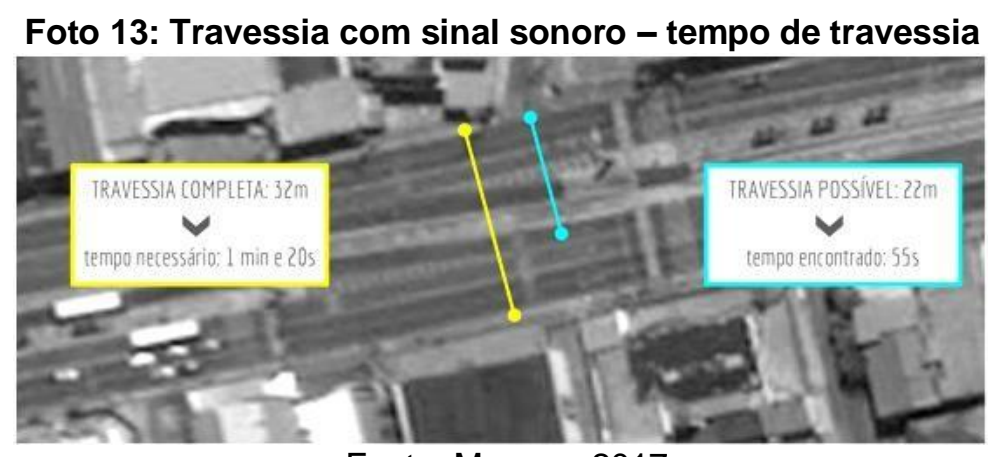

Fonte: Morano, 2017

O medo que as pessoas sentem, é devido ao grande número de acidentes, tanto na via de carros quanto na vida de bicicletas que se encontra junto ao meio-fio. Além disso, fica difícil de ser percebido o som do sinal sonoro por alguns participantes, principalmente, por que a via é frenética e possui muitos sons e ruídos. O sinal sonoro, segundo a NBR 9050, "deve ser capaz de medir automaticamente o ruído momentâneo ao redor do local monitorado, em decibels, para referência, e emitir sons com valores de $10 \mathrm{dBA}$ acima do valor referenciado".

\subsection{Vegetação}

A vegetação é um dos maiores desafios, pois precisa seguir algumas normas para não criarem transtornos e, também, não ferir os pedestres. Segundo a NBR 9050/2015, nas áreas adjacentes às rotas acessíveis e áreas de circulação de pedestres, a vegetação não pode apresentar as seguintes características: a) espinhos ou outras características que possam causar ferimentos. Foi observado que existe plantas com espinhos na calçada do Instituto dos Cegos e, alguns participantes relataram que já se machucaram.

Essa análise foi compilada através de checklist, vídeo e fotos realizadas no percurso. $O$ chekclist foi transformado em um quadro síntese classificando os parâmetros como: 
existente; não existente ou inadequado, além de possíveis soluções para esses itens (Quadro 1).

\section{Quadro 1: Síntese dos Parâmetros avaliados}

\begin{tabular}{|c|c|c|c|}
\hline $\begin{array}{l}\text { PARÄMETROS AVALIADOS NOS } \\
\text { PERCURSOS }\end{array}$ & E & NE & POSSIBILIDADES DE SOLUÇÃO \\
\hline \multicolumn{4}{|l|}{ CALÇADAS } \\
\hline Piso antiderrapante & $\mathrm{x}$ & & $\begin{array}{l}\text { Na NBR 9050, no item 6.3.2, quanto ao revestimento apenas dá essas recomendações: } \\
\text { "Os materiais de revestimento e acabamento devem ter superfície regular, firme, estável, } \\
\text { não trepidante para dispositivos com rodas e antiderrapante, sob qualquer condição (seco } \\
\text { ou molhado)." } \\
\text { Quanto a NBR 16537: "A sinalização tátil de alerta no piso deve atender aos seguintes } \\
\text { requisitos: a) ser antiderrapante, em qualquer condição, devendo ser garantida a condição } \\
\text { antiderrapante durante todo o ciclo de vida da edificação/ambiente, tanto em áreas internas } \\
\text { como externas." }\end{array}$ \\
\hline Faixa para travessia de pedestre; & $\mathrm{x}$ & & \\
\hline $\begin{array}{l}\text { Rebaixamento de calçada para } \\
\text { travessia de pedestre; }\end{array}$ & $\mathrm{x}$ & & Algumas fora do dimensionamento estipulado pela NBR 9050 . \\
\hline Faixa elevada; & & $\mathrm{x}$ & $\begin{array}{l}\text { Poderia ser uma proposta de traffic calming nas travessias próximas as escolas para } \\
\text { PcDV. }\end{array}$ \\
\hline $\begin{array}{l}\text { Alinhamento de rampa com faixa de } \\
\text { pedestre; }\end{array}$ & $\mathrm{x}$ & $x$ & $\begin{array}{l}\text { Aconteceu durante a travessia de o rebaixamento não estar alinhado com a travessia para } \\
\text { o pedestre e sim alinhado para com a ciclovia. }\end{array}$ \\
\hline Travessias livres de obstáculos; & & $x$ & Gelo baiano na travessia principal, para evitar que carros passem para a faixa do pedestre. \\
\hline Travessia sinalizada com piso tátil; & & $\mathrm{x}$ & \\
\hline Faixas de serviço, livre e de acesso; & $x$ & & $\begin{array}{l}\text { Existe, entretanto, é ocupada por postes, orelhões e buracos. Possível remoção dos } \\
\text { obstáculos e conserto dos buracos }\end{array}$ \\
\hline \multicolumn{4}{|l|}{ SINALIZAÇAO } \\
\hline Sinal sonoro em cruzamento; & $x$ & & $\begin{array}{l}\text { Proposta de tempo maior para travessia. Existente em } 2 \text { de } 3 \text { travessias realizadas. } \\
\text { Somente nas travessias da Avenida. nas ruas laterais ao instituto, por exemplo, são } \\
\text { inexistentes. }\end{array}$ \\
\hline $\begin{array}{l}\text { Sinalização tátil nas paradas de ônibus } \\
\text { / ônibus; }\end{array}$ & $x$ & & $\begin{array}{l}\text { Só pode ser identificada na estação elevada. Nas paradas comuns não foi possível } \\
\text { identificar. }\end{array}$ \\
\hline \multicolumn{4}{|r|}{ s } \\
\hline \multicolumn{4}{|l|}{ DIRECIONAL } \\
\hline $\begin{array}{l}\text { No sentido transversal às guias } \\
\text { rebaixadas; }\end{array}$ & $\mathrm{x}$ & & \\
\hline $\begin{array}{l}\text { Na divisa da calçada com o lote - } \\
\text { quando não houver muro; }\end{array}$ & $x$ & & Existente somente em um sentido da via: Av. Bezerra de Menezes-Caucaia. \\
\hline \multicolumn{4}{|l|}{ ALERTA } \\
\hline $\begin{array}{l}\text { Em torno dos obstáculos suspensos } \\
\text { com altura entre } 0,60 \mathrm{~m} \text { e } 2,10 \mathrm{~m} ;\end{array}$ & & $\mathrm{x}$ & Substituir pisos intertravados pelos de alerta. \\
\hline Término e início de rampas e degraus; & $x$ & & \\
\hline $\begin{array}{l}\text { Junto à desníveis e paradas de } \\
\text { ônibus; }\end{array}$ & $\mathrm{x}$ & & Colocar contraste visual. \\
\hline $\begin{array}{l}\text { Sinalização tátil obedece a tabela de } \\
\text { constraste de cores (nbr); } \\
\text { VEGETACAO }\end{array}$ & & $\mathrm{x}$ & Não atendiam as recomendações do item 5.6 da NBR 16.537. Mudar de cor. \\
\hline $\begin{array}{l}\text { Vegetação na passagem raízes e } \\
\text { espinhos: }\end{array}$ & $x$ & & Trocas as plantas presente na mureta do Instituto do Cegos. \\
\hline \multicolumn{3}{|l|}{ OBSTACULOS NO PERCURSO } & ${ }^{*}$ Havia sujeira de cachorro na calçada. \\
\hline $\begin{array}{l}\text { Degraus nas calçadas ocasionadas } \\
\text { por rampas irregulares de garagens; }\end{array}$ & & $\mathrm{x}$ & \\
\hline $\begin{array}{l}\text { Grelha em situação irregular, com } \\
\text { dimensionamento e posicionamento } \\
\text { de abertura inadequados; }\end{array}$ & $x$ & & No final da travessia, existem grelhas e boeiros abertos. Colocar fechamento adequado. \\
\hline Mudança brusca no tipo de piso; & & $\mathrm{x}$ & \\
\hline $\begin{array}{l}\text { Elementos mal posicionados, } \\
\text { obstruindo o passeio (plantas, árvores, } \\
\text { postes e mobiliário); }\end{array}$ & $x$ & & $\begin{array}{l}\text { Modificar posição ou adicionar piso de alerta. Postes interrompendo a referência edificada, } \\
\text { placa de anúncio pregada à um poste. Não recomendado de acordo com o item } 7.8 \text { da } \\
\text { NBR } 16.537 \text {. }\end{array}$ \\
\hline $\begin{array}{l}\text { Inclinação acentuada de calçadas e } \\
\text { desníveis; }\end{array}$ & & $\mathrm{x}$ & \\
\hline Obstáculos temporários; & $\mathrm{x}$ & & Comércio informal, lixos. Estacionar em faixa de serviço. \\
\hline $\begin{array}{l}\text { Veículos estacionados no leito da } \\
\text { calçada; }\end{array}$ & $\mathrm{x}$ & & \\
\hline $\begin{array}{l}\text { Materiais de construção, lixos e } \\
\text { entulhos lançados na calçada; }\end{array}$ & $x$ & & $\begin{array}{l}\text { Fornecer maior número de lixeiras e colocá-las na faixa de serviço. Sacos de lixo e lixeiras } \\
\text { de grande porte que não pertenciam a um mobiliário urbano público }\end{array}$ \\
\hline $\begin{array}{l}\text { Canteiros dispostos inadequadamente } \\
\text { nas calçadas; }\end{array}$ & $\mathrm{x}$ & & $\begin{array}{l}\text { Mudar lugar dos canteiros enquando não há árvore, Somente o buraco pra se colocar e } \\
\text { sem sinalização de piso tátil de alerta. }\end{array}$ \\
\hline
\end{tabular}

Fonte: Morano, 2017

\subsection{Mapa Mental e Entrevista}

Ao final do percurso, foi trabalhado com os participantes, alunos do Instituto dos Cegos, um Mapa Mental do trajeto. Foi discutido com eles sobre o percurso que descrevessem o que mais tinha chamado atenção, um desvio, barulho, cheiro ou até sensações de insegurança e 
medo. Desse modo, depois de coletadas as informações por meio de escritos e gravações, foram feitos desenhos para representar o que havia sido dito.

A primeira situação constatada é de que é quase impossível para uma PcDV ter plena autonomia para se deslocar no trecho, mesmo sendo por alguns já conhecido. Foi possível perceber pelo discurso dos participantes, como a cidade está despreparada para receber pessoas com esse tipo de deficiência. O percurso foi realizado numa via reformada, possui uma estação voltada para atender o Instituto dos Cegos, mas seu entorno apresenta obstáculos, como: placas; postes; estacionamentos; interrupção de piso tátil; comércio informal; mau posicionamento de mobiliário e pouca manutenção. Nas entrevistas, os participantes demonstraram que, além da parte física deste trecho da cidade não ter as condições plenas de acessibilidade, a sociedade também está despreparada para interagir com esse público. Essas pessoas sofrem preconceito, omissão e hostilidade diariamente por serem vulneráveis em relação aos outros. Em entrevista, M. fala:

Quando estou no ônibus e começa a chegar perto da parada do Instituto, as pessoas já me pegam pelo braço, não falam nada... Acham que eu não escuto. E, falam gritando 'o Instituto é na próxima'. Eu fico chateado. Com raiva mesmo. E, respondo que não vou descer aqui. As pessoas acham que a gente não tem outra vida. Que a gente só vem pro Instituto. As vezes não é por mal, todo mundo quer ajudar, mas ninguém fala direito com a gente... Outro dia, eu tava na parada e eu senti que tinha pessoas lá, perguntei se alguém podia me dizer o ônibus que tava vindo, e recebi como resposta o silêncio. É muito triste. As pessoas precisam se colocar no nosso lugar. Trecho entrevista com o M. 32 anos - Baixa Visão.

Criando um Mapa mental, memorizando o lugar dos obstáculos, pontuando referências e reconhecendo-as dia após dia. Com a perda da visão, os outros sentidos ficam aguçados, então esse mapa é feito por aspectos físicos e sensitivos. Foram feitos 10 mapas mentais de participantes, que foram compilados em apenas um mapa o que foi recorrente e percebido pelos participantes (Figura 5).

\section{Figura 5: Compilação dos Mapas Mentais.}

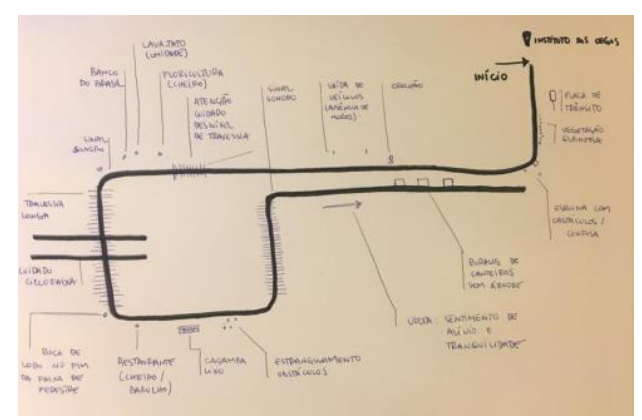

Fonte: Raquel Morano, 2017.

No início do percurso, todos os participantes falaram sobre a placa de trânsito colocada recentemente e, que foi posicionada com uma altura inadequada (Foto 5). Alguns dos participantes já esbarraram nessa placa, principalmente, porque o piso tátil se encontra muito próximo ao poste. Na mesma calçada, há presença de vegetação espinhosa, alguns deles já se arranharam e outros já tinham sido alertados sobre este risco.

Continuando o mapa, todos mencionaram a preocupação e cuidado na esquina pois, existem vários obstáculos. Houve orientação por parte dos participantes de como eles devem andar naquele trecho: "sempre perto da parede, para não ter perigo de se machucar"

Era perceptível a diminuição do passo quando estava chegando próximo a algum obstáculo que estava em seu mapa mental. Interessantes os relatos sobre o calor do sol e a sombra para perceber a aproximação de um obstáculo. Quando a sombra de um edifício acaba e 


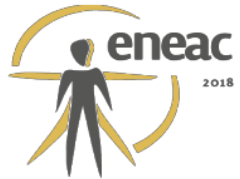

começa o sol, o telefone público estaria próximo. A percepção do sinal sonoro é unânime. É a mais fácil de perceber. Está presente em todos os mapas mentais.

O desnível da travessia foi ultrapassado com atenção por todos e, também, estava presente em vários mapas. Quando a mudança na altura da calçada é brusca, todos já ficam mais atentos e dão mais atenção ao percurso. Depois disso, com a atenção ativada, alguns perceberam o cheiro de uma floricultura e a umidade de um lava-jato, principalmente, porque a calçada estava molhada. Em seguida, o Banco do Brasil também se fez presente em alguns relatos, sendo ponto de referência da outra faixa de pedestre, onde atravessaríamos. A travessia é longa (Foto 13) e muitos deles mencionaram sentimento de aflição, medo, insegurança no dia-a-dia e, alívio por estamos perto deles, principalmente, ao chegar na ciclofaixa "pois, os ciclistas não respeitam a nossa passagem" - palavra de M. 58 anos. Ao chegarmos do outro lado, a faixa de pedestre não estava alinhada com a rampa, e havia uma boca de lobo. Um deles relatou que já tinha "prendido o pé" no buraco.

A presença do restaurante também foi apontada por vários deles, conseguiram perceber que havia cheiro de comida e escutaram conversas e sons de talheres. Há um discurso geral de alívio e tranquilidade ao saber que estamos voltando para o Instituto. O que foi percebido é que, a maioria das coisas que eles lembram e memorizam são obstáculos físicos que podem machucá-los ou que alguns já se machucaram. A preocupação e o medo estão sempre presentes. Isso é um dos principais indícios de como a cidade, embora tenha passado por reformas, não atende completamente esta população. As outras referências foram mérito dos outros sentidos, olfato e audição. E, aqui, fica a pergunta: será que não poderíamos criar referências gentis para essa população?

\section{CONSIDERAÇÔES FINAIS}

A realização do percurso, juntamente com a aplicação da metodologia, foi de grande importância para o entendimento de como as PcDV se relacionam com a cidade. Essa aproximação permitiu uma melhor comparação das recomendações das Normas, Guias e Decretos com o que realmente está sendo aplicado na cidade.

O que foi percebido em relação à infraestrutura desse percurso - e, talvez, pode ser generalizado para a cidade - é que as ações no espaço público estão caminhando em passos lentos para uma acessibilidade eficaz.

Apesar de já ter sido conquistado muito, ainda predomina a falta de fiscalização e manutenção. A acessibilidade é um detalhe, porém, esse detalhe pode dificultar ou até impedir a mobilidade de muitas pessoas. Existem muitos quesitos em conformidade com as normas, mas os problemas existentes geram desconforto, insegura e medo nas PcDV ao caminhar pela cidade.

O que foi percebido em relação a percepção é que cada pessoa é única, tem suas próprias percepções, seus medos individuais, traumas e uma história. E, a sua relação com a cidade, também é única. Porém, o que podemos perceber é que todos os participantes que vivenciaram o percurso procuram entender o espaço e criar suas referências, sejam elas positivass - cheiro, sinal sonoro - ou negativas - buracos, obstáculos. Tudo é referência. A PcDV está sempre na defensiva, esperando as barreiras e desviando delas sempre protegendo o rosto. Apesar do medo e da insegurança de percorrer o espaço urbano, há uma intimidade e uma memória sensitiva altamente aguçada, é assim que seus percursos são traçados diariamente. $\mathrm{E}$, com isso, com a vivência diária, com a fala de outros sujeitos, eles vão construindo a sua própria cidade. Individual. Mas que é entendida por eles de uma maneira rica e possível de se caminhar.

A acessibilidade no meio urbano, e não só em ambientes privados, é essencial para a total inclusão das pessoas com deficiência na sociedade, para que dentro de suas especificidade seja possível efetuarem todas as atividades e se sentirem iguais. A vivência foi de suma 


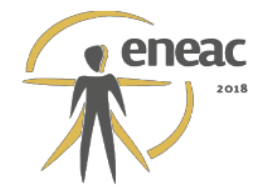

importância para constatar que é essencial conhecer a cidade e seus usuários. Vê-los caminhar e entender qual a melhor forma de se projetar. Compreender que a acessibilidade faz parte do papel social do arquiteto e urbanista.

\section{REFERÊNCIAS BIBLIOGRÁFICAS}

ASSOCIAÇÃO BRASILEIRA DE NORMAS TÉCNICAS. NBR9050: Acessibilidade a edificações, mobiliário, espaços e equipamentos urbanos. Rio de Janeiro, 2015.

ASSOCIAÇÃO BRASILEIRA DE NORMAS TÉCNICAS. NBR16537: Acessibilidade -Sinalização tátil no piso -Diretrizes para elaboração de projetos e instalação.Rio de Janeiro, 2016.

BRASIL. Decreto Federal n. 5.296, de dezembro de 2004. Regulamenta as Leis nos 10.048, de 8 de novembro de 2000, que dá prioridade de atendimento às pessoas que especifica, e 10.098, de 19 de dezembro de 2000, que estabelece normas gerais e critérios básicos para a promoção da acessibilidade das pessoas portadoras de deficiência ou com mobilidade reduzida, e dá outras providências. Brasília, 2000.

BRASIL. Lei no 13.146, de julho de 2015. Institui a Lei Brasileira de Inclusão da Pessoa com Deficiência (Estatuto da Pessoa com Deficiência). Brasília, 2015.

BRADDOCK, David L.; PARISH, Susan L. An institutional history of disability. Department of Disability and Human Development, Universidade de llinois: Chicago, 2000.

CEARÁ. Guia de Acessibilidade: Espaços públicos e edificações.Elaboração: Nadja G.S. Dutra Montenegro; Zilsa Maria Pinto Santiago; Valdemice Costa de Sousa. Fortaleza: SEINFRA-CE, 2009.

DISCHINGER, Marta. Designing for alll senses: Accessible spaces for visually impaired citizens. 2000. 260f. Thesis (for the degree of Doctor of Philosophy) -Department of Space and Process Schoolof Architecture, Chalmers University of Technology, Göteborg, Suécia, 2000.

GODOY, Arllda Schmidt. Introdução à pesquisa qualitativa e suas possibilidades: Uma revisão histórica dos principais autores e obras que refletem esta metodologia de pesquisa em Ciências Sociais. Revista de Administração de Empresas, São Paulo, v. 35, n. 2, p. 57-63. Mar/Abr 1995.

IBGE, Censo Demográfico, 2010: Disponível em http://www.ibge.censo2010.gov.brAcesso em: 01/12/2017.

MAMEDE, Lia. VISITABILIDADE-VIVÊNCIABILIDADE EM ASSENTAMENTOS INFORMAIS um estudo da acessibilidade de percursos urbanos no Conjunto Santa Terezinha, em FortalezaCE. UFRN, 2011.

MORANO, Raquel Pessoa. Relatório da Disciplina Estágio Docência. Programa de PósGraduação em Arquitetura, Urbanismo e Design da Universidade Federal do Ceará. Fortaleza: UFC, 2017.

SANTIAGO, Zilsa Maria Pinto; DO NASCIMENTO, Raquel Martins. Avaliação das Condições de Microacessibilidade física na Avenida Bezerra de Menezes Pós-Transfor. In: Anais do V ENEAC - Encontro Nacional de Ergonomia do Ambiente Construído. Rio de Janeiro: PUC-RJ, 2014.

SECRETARIA DE MOBILIDADE (SeMob). Plano Nacional de Mobilidade. Brasília, 2007.

SILVA, Idari Alves da. Construindo a cidadania: uma análise introdutória sobre o direito à diferença. Dissertação (Mestrado em História Social) - Universidade Federal de Uberlândia, Uberlândia, 2002.

THIBAUD, Jean-Paul. Regards en action. Ethnométhodologie des espaces publics. Bernin: A la Croisée, 2002.

VILLAÇA, Flávio. Espaço Intra-Urbano no Brasil. São Paulo: Ed.Studio Nobel: FAPESP: Licoln Institute, 1998. 